\title{
Health and Social Care During Coronavirus Outbreak: The Exploitation of Long Lasting Memories - LLM Care
}

\author{
Evangelia ROMANOPOULOU ${ }^{\mathrm{a}, 1}$, Vasiliki ZILIDOU ${ }^{\mathrm{a}}$, Sotiria GYLOU ${ }^{\mathrm{a}}$, Ioanna \\ DRATSIOU ${ }^{\mathrm{a}}$, Aikaterini KATSOULI ${ }^{\mathrm{a}}$, Maria KARAGIANNI ${ }^{\mathrm{a}}$, Vasileia \\ PETRONIKOLOU $^{\mathrm{a}}$, Annita VARELLA ${ }^{\mathrm{a}}$ and Panagiotis BAMIDIS ${ }^{\mathrm{a}}$ \\ ${ }^{\mathrm{a}}$ Lab of Medical Physics, School of Medicine, Aristotle University of Thessaloniki, \\ Greece
}

\begin{abstract}
The Covid-19 pandemic has globally introduced a new crisis with severe consequences and led to a series of pandemic-related containment measures, including social distancing and self-isolation may cause significant impact on mental health. This study describes a social care initiative that was actualized during the Covid-19 outbreak with regard to the potential benefits in older adults' quality of life through the use of the Integrated Healthcare System Long Lasting Memories Care (LLM Care), and specifically the web-based cognitive training software. Online questionnaires, assessing various psychosocial and mental health domains, were distributed to 28 older adults before and after the interaction with the software aiming at evaluating the potential positive effect and usability of cognitive training software. Overall, the study demonstrates that the interaction with the web-based cognitive training software during the pandemic plays a significant role in maintaining mental health among older people, through improvements in well-being.
\end{abstract}

Keywords. Covid-19, cognitive training, health care, social care

\section{Introduction}

The Covid-19 pandemic has rapidly spread across all the world, posing the need for unprecedented efforts in order to protect public health [1]. Undoubtedly, a global crisis has been noticed in economic and socio-political levels with severe consequences in well-being and mental health of vulnerable groups of people. The pandemic-related containment measures, along with social distancing and self-isolation may have a significant impact on mental health, especially for older adults [2]. Indeed, the disruption of important daily activities can pose a negative impact on older adults' cognitive condition, impelling to inferior mental health, low quality of life and anxiety [3]. Related studies highlight that $37.1 \%$ of older adults had experienced depression and anxiety

${ }^{1}$ Corresponding Author, Lab of Medical Physics, Medical School, Aristotle University of Thessaloniki, PO Box 376, 54124, Thessaloniki, Greece; E-mail: evangeliaromanopoulou@gmail.com 
during the pandemic [4], while the emotional response of people aged above 60 years was more apparent as compared to other age groups [5].

To this end, sensitization at all levels and efforts to detect and support the mental health care needs of older adults are stressed out [2]. Information and Communication Technology (ICT) offers in response the utilization of various programs/software and solutions to help people live independently and, thus, overcome problems they face in their daily lives by participating in social networks, accessing services and monitoring their health [6]. Cognitive training is considered to be crucial for the prevention of cognitive deterioration, strengthening the cognitive functions and improving quality of life [7]. This study designates an initiative introduced during the Covid-19 outbreak regarding the potential benefits in older adults' quality of life through interaction with a web-based cognitive training software.

\section{Methods}

\subsection{Health and Social Care Ecosystem Long Lasting Memories Care-LLM Care}

The LLM Care [8] is an ICT platform that combines cognitive training exercises (BrainHQ) with physical activity (wFitForAll) and provides evidence-based interventions for improving cognitive functions as well as the overall physical condition. LLM Care was initially exploited in order to deliver the appropriate training for improving the older adults' cognitive and physical health and, thus, resulting in the enhancement of their quality of life and autonomy [9].

The cognitive training environment of LLM Care, BrainHQ [10], is a web-based training software developed by Posit Science and incorporates highly empowering cognitive techniques by providing fully personalized and adaptable cognitive training. The physical training, webFitForAll exergaming platform, developed by the research group of the Medical Physics Laboratory of Aristotle University of Thessaloniki, Greece, within the European Project Long Lasting Memories (LLM) [11], provides specialized physical training in order to improve or to maintain individuals' physical condition.

\subsection{Participants}

Twenty-eight (28) older adults (mean age 67.14 years) participated in this study. A majority of the participants were female $(67.9 \%$ ) while $32.1 \%$ were males. Also, $67.9 \%$ were married, $7.1 \%$ unmarried and $21.4 \%$ widowed. The subject pool was selected under the social care initiative provided through Covid-19 outbreak.

\subsection{Intervention}

The cognitive training software BrainHQ was used as an interactive and online tool to cognitively train the participants. The intervention was set to 12 weeks from June to August 2020 (32 sessions, 2-4 times/week, min 30’). 


\subsection{Measures and procedure}

Online questionnaires were distributed to participants including the scope, purpose of the study and consent forms, while specific instructions and guidance were also provided in respect to the cognitive training. Psychological assessments included within the online questionnaires were distributed every two weeks in order to assess a variety of psychosocial and mental health domains. Specifically, the assessments comprised of the World Health Organisation-Five Well-Being Index (WHO-5), a short self-reported measure of current mental wellbeing [12], the Short Anxiety Screening Test (SAST) to standardize the detection of anxiety disorder [13], the System Usability Scale (SUS) for measuring the usability [14] and the Impact Factor Event Scale (IES-R) for stress reactions after traumatic events [15].

\subsection{Statistical Analysis}

Statistical tests were performed using SPSS (IBM SPSS Statistics 25). To assess the reliability of WHO-5 and IES-R questionnaires, Cronbach's alpha coefficients for internal consistency and Pearson's rho correlation coefficients were calculated. As normality assumption was met (i.e. Shapiro-Wilk test), paired sample T-test, one-way repeated-measures of ANOVA were utilized to test the statistically significant differences between WHO-5, IERS-R scores and the variables of gender, age, education and marital status.

\section{Results}

The Cronbach's alpha was measured to examine the internal consistency of WHO-5 scores (cf. Table 1). These findings indicate that the answer for each question is consistent with the others and they do not overlap.

Table 1. Cronbach's alpha, Mean, Standard Deviation of WHO-5 evaluations.

\begin{tabular}{ccc}
\hline WHO-5 Evaluations & Cronbach's Alpha & Mean \pm SD \\
\hline $1^{\text {st }}$ evaluation & .89 & $56 \pm 25.97$ \\
$2^{\text {nd }}$ evaluation & .89 & $63.71 \pm 24.05$ \\
$3^{\text {rd }}$ evaluation & .85 & $63.43 \pm 22.14$ \\
$4^{\text {th }}$ evaluation & .89 & $66 \pm 22.78$ \\
$5^{\text {th }}$ evaluation & .90 & $66.57 \pm 23.43$ \\
\hline
\end{tabular}

A repeated measure of ANOVA was conducted with age as the between-subjects factor and WHO-5 scores as the within-subjects factor. There was found a significant main effect of WHO-5 scores $(\mathrm{F}(4,88)=2.609, \mathrm{p}=.041)$ and a significant increase in the WHO-5 scores for the participants $71+$ years old across: a) WHO-5 scores from $1^{\text {st }}$ evaluation $(\mathrm{M}=52, \mathrm{SD}=22.15)$ compared to WHO-5 scores from $2^{\text {nd }}$ evaluation $(\mathrm{M}=69.6$, $\mathrm{SD}=24.96), \mathrm{t}(9)=-2.52, \mathrm{p}=.033$ and $\mathrm{b}) \mathrm{WHO}-5$ scores from $1^{\text {st }}$ evaluation $(\mathrm{M}=52$, $\mathrm{SD}=22.15)$ compared to the WHO-5 scores from $5^{\text {th }}$ evaluation $(\mathrm{M}=74, \mathrm{SD}=20.93)$, $\mathrm{t}(9)=-2.607, \mathrm{p}=.028$ that means $71+$ years old participants had more depression symptoms in the beginning of the study in comparison with $2^{\text {nd }}$ evaluation and the $5^{\text {th }}$ evaluation.

Cronbach's $\alpha$ of the total scale was 0.82 and for subscales of intrusion, avoidance and hyperarousal was $0.78,0.76$, and 0.68 , respectively. The convergent validity was supported by positive correlations between the subscales (intrusion, avoidance, 
hyperarousal) and Pearson correlation between IES-R scores from $1^{\text {st }}$ and $5^{\text {th }}$ evaluation showed that all IES-R scores were remarkably consistent across the two occasions and significantly correlated (cf. Table 2).

Table 2. Alpha Coefficients, Subscale Means, and Test-Retest Reliability of IES-R Subscales.

\begin{tabular}{cccc}
\hline Subscales & Cronbach's Alpha & Mean \pm SD & Pearson's Correlation Coefficient \\
\hline Intrusion & 0.78 & $0.77 \pm 0.35$ & $0.548^{\mathrm{a}}$ \\
Avoidance & 0.76 & $0.90 \pm 0.35$ & $0.511^{\mathrm{a}}$ \\
Hyperarousal & 0.68 & $0.94 \pm 0.74$ & $0.574^{\mathrm{a}}$ \\
\hline $\mathrm{SD}=$ standard deviation. & & &
\end{tabular}
${ }^{\mathrm{a}} \mathrm{p}<.05$

There was found that women $(\mathrm{M}=6.89, \mathrm{SD}=5.14)$ had higher intrusion scores than men $(\mathrm{M}=3, \mathrm{SD}=2.45), \mathrm{t}(26)=2.760, \mathrm{p}=.042$, that means women had more unbidden thoughts and images, troubled dreams, strong pangs or waves of feelings, and repetitive behavior than men during the study. Moreover, there was a statistically significant difference between intrusion scores and marital status as determined by one-way ANOVA $(\mathrm{F}(2,26)=7.022, \mathrm{p}=.004)$. In particular, post hoc tests revealed that the intrusion scores for married $(M=3.79, S D=3.05)$ were lower compared to the unmarried $(M=12.5$, $\mathrm{SD}=10.61), \mathrm{p}=.023$ and widowed $(\mathrm{M}=9, \mathrm{SD}=4.65), \mathrm{p}=.032$ respectively, which means that married had less intrusive images, thoughts and feelings during the interventions in comparison with unmarried and widowed participants.

When comparing hyperarousal scores and marital status, significant differences determined by one-way ANOVA $(\mathrm{F}(2,26)=6.991, \mathrm{p}=.004)$. After Bonferroni post hoc test, there was observed a significantly lower difference between married $(\mathrm{M}=3.68$, $\mathrm{SD}=2.14)$ and widowed $(\mathrm{M}=8.5, \mathrm{SD}=5.24), \mathrm{p}=.008$ that means widowed participants experienced and acted with more anger and irritability than married participants.

\section{Discussion}

This study aimed to investigate the effect on well-being through personalized cognitive training provided by an interactive online tool. In particular, participants' outcomes indicated an overall improvement in well-being levels from the beginning until the end of the intervention, between the first and fifth evaluation, while an initial improvement was already observed between the first and the second evaluation of older adults ageing 71 and higher $[7,16]$. This improvement is possibly related to the exploitation of new technologies and serious games, which contribute to increasing aspects of quality of life, and, in particular, they have a positive effect on participants' proactivity in their daily lives [17]. The results also seem to have a connection between the age of the examined population and the effect of experiencing events, which is associated with intrusive emotions and thoughts. To this end, the engagement with serious games acted as an enhancer for older adults, who had supporting social networks (marital status), mitigating the impact of negative thoughts (intrusion) and emotions (hyperarousal) among this population [15]. In the light of this, proactive engagement with the LLM Care platform provides a significant effect in the experience of stressful situations like Covid-19.

\section{Conclusions}

The Covid-19 crisis has led day care centers, institutions and basic support services for older adults or vulnerable groups to face significant issues. Mitigation measures globally 
affected overall well-being and mental health. The aim of this action was to actively engage older people with cognitive training and improve aspects of their quality of life. To this end, the program successfully achieved the challenge to maintain mental health among older people during Covid-19, through improvements in overall well-being.

\section{Acknowledgements}

This research is supported by the business exploitation scheme of the ICT-PSP funded project LLM, namely, LLM Care which is a self-funded initiative at the Aristotle University of Thessaloniki (www.llmcare.gr). The authors would like to thank all the participants, as well as all facilitators that contributed to this study and especially Maria Metaxa and Foteini Dolianiti.

\section{References}

[1] Radwan E, Radwan A, Radwan W. Challenges Facing Older Adults during the COVID-19 Outbreak. European Journal of Environment and Public Health 2021;5(1):em0059.

[2] Banerjee D. The impact of Covid-19 pandemic on elderly mental health. International Journal of Geriatric Psychiatry. 2020 May; 35:1466-1467.

[3] Santini ZI, Jose PE, York Cornwell E, Koyanagi A, Nielsen L, Hinrichsen C et al. Social disconnectedness, perceived isolation, and symptoms of depression and anxiety among older Americans (NSHAP): a longitudinal mediation analysis. The Lancet Public Health. 2020;5:62-70.

[4] Meng H, Xu Y, Dai J, Zhang Y, Liu B, Yang H. Analyze the psychological impact of COVID-19 among the elderly population in China and make corresponding suggestions. Psychiatry research. 2020 Jul;289:112983.

[5] Qiu J, Shen B, Zhao M, Wang Z, Xie B, Xu Y. A nationwide survey of psychological distress among Chinese people in the COVID-19 epidemic: implications and policy recommendations. General psychiatry. 2020 Mar;33(2).

[6] Hülür G, Macdonald B. Rethinking social relationships in old age: Digitalization and the social lives of older adults. American Psychologist, May-Jun 2020;75(4):554-566.

[7] Belkacem AN, Jamil N, Palmer JA, Ouhbi S, Chen C. Brain Computer Interfaces for Improving the Quality of Life of Older Adults and Elderly Patients. Frontiers in neuroscience 14:692.

[8] LLM Care Homepage, Available at: www.llmcare.gr; Accessed January 9, 2021.

[9] Bamidis P, Fissler P, Papageorgiou SG, Zilidou V, Konstantinidis E, Billis A, Romanopoulou E, Karagianni M, Beratis I, Tsapanou A, et al. Gains in cognition through combined cognitive and physical training: the role of training dosage and severity of neurocognitive disorder. Frontiers in Aging Neuroscience. 2015 Aug; 7;7:152.

[10] BrainHQ Homepage, Available at: www.brainhq.com, Accessed January 9, 2021.

[11] Long Lasting Memories Homepage, Available at: http://www.longlastingmemories.eu, Accessed January 9, 2021.

[12] Bonsignore M, Barkow K, Jessen F, et al. Validity of the five-item WHO Well-Being Index (WHO-5) in an elderly population.Eur Arch Psychiatry Clin Neurosci 2001;251(12):II27-31.

[13] Sinoff G, Ore L, Zlotogorsky D, Tamir A. Short Anxiety Screening Test - a brief instrument for detecting anxiety in the elderly. Int J Geriatr Psychiatry. 1999;14:1062-1071.

[14] Katsanos C, Tselios N, Xenos M. Perceived usability evaluation of learning management systems: a first step towards standardization of the System Usability Scale in Greek. Proceedings of the $16^{\text {th }}$ Panhellenic Conference on Informatics IEEE; 2012 Oct;302-307.

[15] Mystakidou K, Tsilika E, Parpa E, Galanos A, Vlahos L. Psychometric properties of the Impact of Event Scale in Greek cancer patients. Journal of Pain and Symptom Management. 2007 Apr 1;33(4):454-61.

[16] Konstantinidis EI, Billis A, Hlauschek W, Panek P, Bamidis PD. Integration of cognitive and physical training in a smart home environment for the elderly people. Stud Health Technol Inform. 2010;160:5862.

[17] Nguyen TT, Ishmatova D, Tapanainen T, Liukkonen TN, Katajapuu N, Makila T, Luimula M. Impact of serious games on health and well-being of elderly: a systematic review. Proceedings of the $50^{\text {th }}$ Hawaii International Conference on System Sciences; 2017 Jan 4. 